\title{
Production of poly (3-hydroxybutyrate-co-4-hydroxybutyrate) by Burkholderia sacchari using wheat straw hydrolysates and gamma-butyrolactone
}

M. Teresa Cesário ${ }^{a,}$, Rodrigo S. Raposo ${ }^{a}$, M. Catarina M.D. de Almeida ${ }^{a, c}$, Frederik van Keulen $^{\mathrm{b}}$, Bruno S. Ferreira ${ }^{\mathrm{b}}$, João P. Telo ${ }^{d}$, M. Manuela R. da Fonseca ${ }^{\mathrm{a}}$

a IBB-Institute for Biotechnology and Bioengineering, Instituto Superior Técnico, Universidade de Lisboa, Av. Rovisco Pais, 1049-001 Lisboa, Portugal

${ }^{\mathrm{b}}$ Biotrend- Inovação e Engenharia em Biotecnologia, S.A., Biocant Park, Núcleo 04 - Lote 2, 3060-197 Cantanhede, Portugal

'CIIEM-Centro de Investigação Interdisciplinar Egas Moniz, ISCSEM, Campus Universitário, Quinta da Granja, 2829-511 Monte de Caparica, Portugal

${ }^{d}$ Centro de Química Estrutural, Instituto Superior Técnico, Universidade de Lisboa, Av. Rovisco Pais, 1049-001 Lisboa, Portugal

\section{Abstract}

Burkholderia sacchari DSM 17165 is able to grow and produce poly(3-hydroxybutyrate) both on hexoses and pentoses. In a previous study, wheat straw lignocellulosic hydrolysates (WSH) containing high $\mathrm{C} 6$ and $\mathrm{C} 5$ sugar concentrations were shown to be excellent carbon sources for $\mathrm{P}(3 \mathrm{HB})$ production.

Using a similar feeding strategy developed for $\mathrm{P}(3 \mathrm{HB})$ production based on $\mathrm{WSH}$, fedbatch cultures were developed aiming at the production of the copolymer $\mathrm{P}(3 \mathrm{HB}-\mathrm{co}-$ 4HB) (poly(3-hydroxybutyrate-co-4-hydroxybutyrate)) by $B$. sacchari. The ability of this

Corresponding author. Tel.: +35121 8419137; Fax: +351218419062.

e-mail address: teresa.cesario@tecnico.ulisboa.pt 
strain to synthesize $\mathrm{P}(3 \mathrm{HB}-\mathrm{co}-4 \mathrm{HB})$ was first shown in shake flasks using gammabutyrolactone $(\mathrm{GBL})$ as precursor of the $4 \mathrm{HB}$ units.

Fed-batch cultures using glucose as carbon source (control) and GBL were developed to achieve high copolymer productivities and $4 \mathrm{HB}$ incorporations. The attained $\mathrm{P}(3 \mathrm{HB}-$ co- $4 \mathrm{HB}$ ) productivity and $4 \mathrm{HB}$ molar $\%$ were $0.7 \mathrm{~g} /(\mathrm{L} \cdot \mathrm{h})$ and 4.7 molar $\%$, respectively. The $4 \mathrm{HB}$ incorporation was improved to 6.3 and 11.8 molar $\%$ by addition of $2 \mathrm{~g} / \mathrm{L}$ propionic and acetic acid, respectively. When WSH were used as carbon source under the same feeding conditions, the values achieved were $0.5 \mathrm{~g} /(\mathrm{L} \cdot \mathrm{h})$ and 5.0 molar \%, respectively.

Burkholderia sacchari, a strain able to produce biopolymers based on xylose-rich lignocellulosic hydrolysates, is for the first time reported to produce $\mathrm{P}(3 \mathrm{HB}-\mathrm{co}-4 \mathrm{HB})$ using gamma butyrolactone as precursor.

Keywords: Burkholderia sacchari; poly(3-hydroxybutyrate-co-4-hydroxybutyrate); wheat straw lignocellulosic hydrolysates 


\section{Introduction}

Several bacteria are able to synthesize polyhydroxyalkanoates (PHA) for carbon and energy storage. This generally happens in response to stress or when exogenous carbon sources are provided in excess and growth is impaired by the lack of at least one essential nutrient like nitrogen, oxygen, phosphorous or magnesium [1]. PHAs accumulate in the cytoplasm in the form of inclusion bodies (PHA granules). The most common PHA is the homopolymer poly 3hydroxybutyrate $\mathrm{P}(3 \mathrm{HB})$ which is formed by the biological condensation of the monomer 3-hydroxybutyric acid. In the latest years, about 150 monomers other than 3-hydroxybutyric acid have been detected as building blocks of bacterial PHAs [2-3]. These monomers are generally incorporated in the polyester chain together with 3-hydroxybutyric acid, forming random copolymers or even polyester blends [4-5]. The co-monomers can be short chain length (scl-PHA, C3-C5) such as 3-hydroxyvalerate (3HV), 4-hydroxybutyrate (4HB), 3hydroxypropionate (3HP) and 4-hydroxyvalerate (4HV) or medium chain length monomers (mcl- PHA, C6-C14) such as 3-hydroxyhexanoate (3HHx) or 3hydroxyoctanoate, (3HO) [6-7]. Incorporation of a particular hydroxyalkanoic acid other than 3- hydroxybutyric acid into the polymer chain depends on the available carbon sources. Most hydroxyalkanoic acid monomers are produced based on carbon sources with a related chemical structure and fed as the sole carbon source or as a cosubstrate $[1,8]$. 
$\mathrm{P}(3 \mathrm{HB}-\mathrm{co}-4 \mathrm{HB})$ is a copolymer that exhibits a wide variety of mechanical properties from hard crystalline plastic to very elastic rubber depending on the molar fraction of the $4 \mathrm{HB}$ monomer in the polymeric chain [9]. For the majority of the uses this is an advantage as compared to the homopolymer $\mathrm{P}(3 \mathrm{HB})$. In fact, $\mathrm{P}(3 \mathrm{HB})$ presents high stiffness and crystallinity which limit some of its applications and also its processability. Besides the attractive mechanical properties, the copolymer $\mathrm{P}(3 \mathrm{HB}-\mathrm{co}-4 \mathrm{HB})$ and also the homopolymer $\mathrm{P}(4 \mathrm{HB})$ possess adequate properties for application in the medical and pharmaceutical fields, namely good biocompatibility and a well-tolerated inflammatory response [10].

Up till now, few wild-type bacteria have been reported to produce $\mathrm{P}(3 \mathrm{HB}-\mathrm{co}-$ 4HB). Examples are Cupriavidus necator former Ralstonia eutropha [11-12], Alcaligenes latus [13-14], Comamonas acidovorans ([14-16], Comamonas testosteronii [17] and Hydrogenophaga pseudoflava [18]. Recombinant E. coli has also been used to obtain $\mathrm{P}(3 \mathrm{HB}-\mathrm{co}-4 \mathrm{HB})$ with $2.8 \mathrm{~mol} \% 4 \mathrm{HB}$ [19] as well as to produce the homopolymer $\mathrm{P}(4 \mathrm{HB})[10]$, for medical purposes at Tepha Inc. (Cambridge, MA, USA).

In this work, the ability of Burkholderia sacchari DSM 17165 to accumulate the copolymer $\mathrm{P}(3 \mathrm{HB}-\mathrm{co}-4 \mathrm{HB})$ upon addition of an adequate precursor is reported. This strain was isolated from sugar cane plantations and was shown to be able to grow and accumulate $\mathrm{P}(3 \mathrm{HB})$ both on hexoses and pentoses [20] . Recently, fed-batch cultivations aiming at $\mathrm{P}(3 \mathrm{HB})$ production using this strain and wheat straw hydrolysates (rich in hexose and xylose), as carbon source have been described [21]. Very high productivities of $1.6 \mathrm{~g} /(\mathrm{L} \mathrm{h})$ were attained corresponding to a polymer concentration and a polymer cell content of $84 \mathrm{~g} / \mathrm{L}$ 
and $68 \% \mathrm{~g} \mathrm{P}(3 \mathrm{HB}) / g$ cell-dry weight $(\mathrm{CDW})$, respectively. In a recent study with B. sacchari, Mendonça et al., 2013 confirmed the ability of this strain to incorporate the $3 \mathrm{HV}, 4 \mathrm{HB}$ and $3 \mathrm{HHx}$ monomers upon the addition of specific co-substrates along with glucose namely odd-chain fatty acids, 4-hydroxybutyric acid and hexanoic acid, respectively [22]. B. sacchari IPT 189 has also been reported in literature to produce the copolymer $\mathrm{P}(3 \mathrm{HB}-\mathrm{co}-3 \mathrm{HV})$ when grown in sucrose and propionic acid [23].

In this work, high density fed-batch cultivations were carried out to produce the copolymer $\mathrm{P}(3 \mathrm{HB}-\mathrm{co}-4 \mathrm{HB})$ using $\mathrm{WSH}$ as major carbon source and gammabutyrolactone as precursor. High $\mathrm{P}(3 \mathrm{HB}-\mathrm{co}-4 \mathrm{HB})$ productivities and $4 \mathrm{HB}$ incorporations of ca $5 \%(\mathrm{~mol} / \mathrm{mol})$ were attained. This is the first study reporting the production of $\mathrm{P}(3 \mathrm{HB}-\mathrm{co}-4 \mathrm{HB})$ by Burkholderia sacchari in high density fedbatch cultivations. Moreover, lignocellulosic agricultural residues were shown to be upgradable to value-added biocommodities, using a biorefinery approach.

\section{Materials and Methods}

\subsection{Microorganism}

Burkholderia sacchari DSM 17165, a strain able to grow and accumulate large amounts of PHAs on hexoses and pentoses, namely glucose, xylose and arabinose, was used throughout this work. 


\subsection{Cultivation media and carbon source}

Burkholderia sacchari DSM 17165 was cultivated in basal mineral medium as previously described [21]. Glucose was used as model carbon source during the preliminary assays (shake flasks) to choose the best $4 \mathrm{HB}$ precursor and to determine the effect of the precursor concentration on the maximum specific cell growth rate, total biomass and polymer concentrations and polymer composition. Moreover, glucose was used as a reference carbon source in fedbatch cultivations carried out in $2 \mathrm{~L}$ stirred-tank reactors to produce the copolymer $\mathrm{P}(3 \mathrm{HB}-\mathrm{co}-4 \mathrm{HB})$ with the concomitant addition of the precursor gamma-butyrolactone (GBL).

Finally, a concentrated wheat straw hydrolysate (WSH), delivered by biorefinery .de $\mathrm{GmbH}$, containing $465.3 \mathrm{~g} / \mathrm{L}$ glucose, $146.3 \mathrm{~g} / \mathrm{L}$ xylose and $41.5 \mathrm{~g} / \mathrm{L}$ arabinose [21] and free of inhibitors was used as C-source for P(3HB-co-4HB) production in high-cell-density cultures by applying the same feeding strategy as with glucose.

\subsection{Strain storage and inoculum preparation}

Cultures of $B$. sacchari were stored at $-80^{\circ} \mathrm{C}$ in $2 \mathrm{~mL}$ cryovials containing $300 \mu \mathrm{L}$ of glycerol and $1500 \mu \mathrm{L}$ of a previously grown liquid culture in the late exponential phase prepared with seeding medium [24] and supplemented with $20 \mathrm{~g} / \mathrm{L}$ of xylose. The inocula for the shake flask experiments were prepared by transferring the content of the cryovials to $500 \mathrm{~mL}$ shake flasks containing 50 $\mathrm{mL}$ of seeding medium supplemented with $10 \mathrm{~g} / \mathrm{L}$ of glucose or xylose, and 
incubated at $30^{\circ} \mathrm{C}$ in an orbital incubator (Infors AG, Switzerland) at $170 \mathrm{rpm}$ for 12 hours.

\subsection{Culture conditions}

\subsubsection{Shake flask assays}

\subsubsection{Selection of the precursor}

Gamma-butyrolactone (GBL) and 1,4-butanediol were tested as precursors for the synthesis of the $4 \mathrm{HB}$ monomer by $B$. sacchari. Cells were grown at $30^{\circ} \mathrm{C}$ on a shaking incubator (170 rpm) in $500 \mathrm{~mL}$ flasks containing $100 \mathrm{~mL}$ seeding medium with $20 \mathrm{~g} / \mathrm{L}$ glucose. The initial OD was 1.0. The precursors were added at a concentration of $5 \mathrm{~g} / \mathrm{L}$ after $6 \mathrm{~h}$ incubation when the OD was approximately 5.0, i.e. before the onset of polymer accumulation. Growth and production were followed during $27 \mathrm{~h}$.

\subsubsection{Effect of GBL concentration on cell growth}

The effect of GBL concentration on cell growth was studied by varying the concentration from 0 to $40 \mathrm{~g} / \mathrm{L}$ at an initial glucose concentration of $40 \mathrm{~g} / \mathrm{L}$. Cells were grown in $500 \mathrm{~mL}$ Erlenmeyer flasks containing $100 \mathrm{~mL}$ seeding medium on a shaking incubator at $30^{\circ} \mathrm{C}$ and $170 \mathrm{rpm}$. The initial $\mathrm{OD}$ was $0.5 . \mathrm{GBL}$ was added at the beginning of the assay. Cell growth was followed during the first 7 h of growth until the OD was approximately 5.0. 


\subsubsection{Effect of glucose and GBL concentrations on the copolymer production}

and composition.

The effect of glucose and GBL concentrations on the polymer production and composition was investigated in one-step shake flask cultivations. Cells were grown at $30^{\circ} \mathrm{C}$ in an orbital incubator $(170 \mathrm{rpm})$ in $500 \mathrm{~mL}$ flasks containing 100 $\mathrm{mL}$ seeding medium and different concentrations of glucose $(0-20 \mathrm{~g} / \mathrm{L})$ and GBL (0-15 g/L). The initial OD was 0.6. GBL was added in the beginning of the assay. Growth, production and polymer composition were followed during $52 \mathrm{~h}$. At the end of the assay cells were harvested and the polymer extracted and purified (c.f. section 2.5.9). The polymer composition was determined through GC analysis of the monomers after acidic methylation of the polymer.

\subsubsection{Fed-batch cultivations}

Fed-batch cultivations for the production of the copolymer $\mathrm{P}(3 \mathrm{HB}-\mathrm{co}-4 \mathrm{HB})$ were carried out in 2L stirred-tank reactors (STRs) (New Brunswick Bioflo 115) operated using the BioCommand Batch Control software which enabled control, monitoring and data acquisition. The pH was controlled at 6.8 with $28 \% \mathrm{NH}_{4} \mathrm{OH}$ and $2 \mathrm{M} \mathrm{HCl}$ solutions. The aeration rate used was $3.6 \mathrm{Lair} / \mathrm{min}$ and the temperature $32{ }^{\circ} \mathrm{C}$. The dissolved oxygen set-point was $20 \%$ saturation and the maximum agitation speed was $1200 \mathrm{rpm}$. The inoculum (5 \% v/v) was prepared using $500 \mathrm{~mL}$ baffled flasks containing $65 \mathrm{~mL}$ of seeding medium. Each flask was inoculated with one cryovial, supplemented with $20 \mathrm{~g} / \mathrm{L}$ of glucose and incubated during $12 \mathrm{~h}$ at $30^{\circ} \mathrm{C}$ and $170 \mathrm{rpm}$. The initial volume of the fed-batch culture was $1.3 \mathrm{~L}$. 
The fed-batch mode of operation was carried out using an automated C-source feeding regime based on the decrease of the stirring speed which happens due to the increase of the dissolved oxygen concentration as a result of $\mathrm{C}$-source exhaustion (DO stat) [21]. The stirring speed at which feeding was triggered was set at $900 \mathrm{rpm}$. The feeding solution consisted either of a solution of glucose $600 \mathrm{~g} / \mathrm{L}$ or wheat straw hydrolysate containing $465.3 \mathrm{~g} / \mathrm{L}$ glucose, $146.3 \mathrm{~g} / \mathrm{L}$ xylose and $41.5 \mathrm{~g} / \mathrm{L}$ arabinose. GBL was added during the accumulation phase. A first pulse was added manually at a cell dry weight (CDW) of 75-80 g/L to attain a GBL concentration in the culture medium of ca. $8 \mathrm{~g} / \mathrm{L}$. Thereafter the precursor was added continuously at a rate of $2.3 \mathrm{~g} / \mathrm{h}$ using a peristaltic pump (Pharmacia LKB Pump P-1).

Phosphate limitation was imposed to promote polymer accumulation as in the assays for the homopolymer production [21]. Under these cultivation conditions, phosphate became the limiting substrate when the cell concentration reached approximately $35 \mathrm{~g} / \mathrm{L}$ CDW. Culture samples were periodically harvested in order to analyze the biomass concentration, polymer concentration and composition as well as sugar and GBL concentrations. The polymer composition was determined by GC analysis after methanolysis, using the polymer extracted from the cells. The results obtained were confirmed by ${ }^{1} \mathrm{H}$ NMR. 


\subsection{Analytical methods}

\subsubsection{Cell dry weight determination}

Cell dry weight (CDW) was determined by centrifuging $1.2 \mathrm{~mL}$ of culture broth in a Sigma 1-15 P microcentrifuge (9168 x g during $4 \mathrm{~min})$ using a previously dried and weighted microtube. The pellet was washed with distilled water and dried at $62{ }^{\circ} \mathrm{C}$ in a Memmert oven (Model 400) until constant weight.

\subsubsection{Sugar quantification}

Glucose, xylose and arabinose as well as phosphate concentrations were determined by HPLC as described in a previous publication [21].

\subsubsection{Gamma-butyrolactone (GBL) quantification}

The GBL (99+\%, Acros organics) concentration in the culture medium, was determined by gas chromatography (GC). Two milliliters of the culture broth were centrifuged using a Sigma 1-15 P microcentrifuge (9168 g for $5 \mathrm{~min}$ ). Subsequently, $1.0 \mathrm{~mL}$ of the supernatant was transferred to $10 \mathrm{~mL}$ Pyrex hermetic test tubes and vortexed for $1 \mathrm{~min}$ with $2.0 \mathrm{~mL}$ of a chloroform solution containing $0.44 \%(\mathrm{w} / \mathrm{v})$ methyl hexanoate as the internal standard $(99 \%$, Aldrich). After centrifugation (Sigma 2-15 laborzentrifugen-B. Braun) at 2800g for 5 min, $1 \mu \mathrm{L}$ sample of the organic phase was analyzed in a gas chromatograph (Agilent Technologies 5890 series II) equipped with a FID detector and a 7683B injector. The capillary column was a HP-5 from Agilent J\&W Scientific, $30 \mathrm{~m}$ in length and $0.32 \mathrm{~mm}$ of internal diameter. The oven, 
injector and detector temperatures were kept constant at $60^{\circ} \mathrm{C}, 120^{\circ} \mathrm{C}$ and 150 ${ }^{\circ} \mathrm{C}$, respectively. Data acquisition and integration were performed by a Shimadzu CBM-102 communication Bus Module and Shimadzu GC Solution software (Version 2.3), respectively. Calibration curves were obtained by mixing $1.0 \mathrm{~mL}$ GBL solutions in basal mineral medium with a $2.0 \mathrm{~mL}$ chloroform solution containing the internal standard and following the same protocol described above.

\subsubsection{HB monomer quantification by GC}

For the determination of the $3 \mathrm{HB}$ concentration, aliquots of culture broth were withdrawn and centrifuged. The cell pellet was washed with distilled water and frozen. The frozen cell pellet was subsequently suspended in $1.0 \mathrm{~mL}$ chloroform and this suspension mixed with $1.0 \mathrm{~mL}$ of an acidic methanol solution containing the internal standard (97 mL of methanol, $3 \mathrm{~mL}$ of $\mathrm{H}_{2} \mathrm{SO}_{4} 95-97 \%$ and $0.3 \mathrm{~g}$ of hexanoic acid). After vortexing for $1 \mathrm{~min}$, the preparation was incubated for $5 \mathrm{~h}$ at $100^{\circ} \mathrm{C}$ in a Memmert $\mathrm{GmbH}$ oven (Model 200). After cooling, $1 \mathrm{~mL}$ of a $60 \mathrm{~g} / \mathrm{L}$ solution of $\mathrm{Na}_{2} \mathrm{CO}_{3}$ was added for sample neutralization and the samples were vortexed for $1 \mathrm{~min}$. These preparations were subsequently centrifuged at $2800 \mathrm{~g}$ for $5 \mathrm{~min}$. Samples of the organic phase were analyzed in a gas chromatograph (Agilent Technologies 5890 series II) using the same equipment and conditions as described above for the GBL determination. Peak identification was achieved using as standard 3methyl hydroxybutyrate (Sigma). Calibration curves were obtained using samples of $\mathrm{P}(3 \mathrm{HB})$ produced previously which were subjected to the same methylation process as the cells. 


\subsubsection{HB monomer quantification by GC}

The 4-hydroxybuyrate concentration was determined by GC using the polymer after its extraction and purification. One $\mathrm{mL}$ of a PHA solution $(6 \% \mathrm{w} / \mathrm{v})$ was mixed with $1.0 \mathrm{~mL}$ of the acidic methanol solution and was then subjected to acidic methanolysis as described in paragraph 2.5.4. Peak identification and quantification was achieved using as standard methyl-4-hydroxybutyrate synthesized from sodium-4-hydroxybutyrate (Atlantic Chemicals) by acidic methanolysis. The presence of the $4 \mathrm{HB}$ monomer in the polymer was confirmed by ${ }^{1} \mathrm{H}$ NMR analysis.

\subsubsection{Nuclear magnetic resonance analysis ( ${ }^{1} \mathrm{H}$ NMR)}

Samples of purified polymer (ca. $35 \mathrm{mg}$ ) were dissolved in deuterated chloroform $(0.5 \mathrm{~mL})$ and the ${ }^{1} \mathrm{H}$ NMR spectra recorded in a Bruker AVANCE III spectrometer operating at $400 \mathrm{MHz}$. Forty eight spectra were accumulated for each determination. Chemical shifts are given in ppm relative to the signal of the solvent (7.26 ppm).

\subsubsection{Molecular weight determination}

The average molecular weight of the polymer was determined at TECNALIA (Miñano - Araba, Spain) by Size Excursion Cromatography (SEC). The polymer sample (15 mg) was dissolved in $3 \mathrm{~mL}$ of chloroform during $15 \mathrm{~h}$ at room temperature under agitation in a $15 \mathrm{ml}$ glass vial with PE caps. The solutions were then filtered using a Teflon filter with a pore diameter of $0.2 \mu \mathrm{m}$ and introduced in a SEC system (Waters Millenum) composed of three columns assembled in series (PLgel $5 \mu \mathrm{m}$ Guard, Polymer Laboratories, 50 × 7.5 mm; 
PLgel 5 um 104 Å, Polymer Laboratories, 300 x 7.5 mm,; PLgel 5 um $500 \AA$, Polymer Laboratories, $300 \times 7.5 \mathrm{~mm}$ ). Elution was achieved at $30^{\circ} \mathrm{C}$, at flow rate of $1 \mathrm{~mL} / \mathrm{min}$ and using chloroform under degassed helium as mobile phase. The refractive index was used for detection (Waters 2410).

\subsubsection{Thermal properties}

The thermal properties of the polymer were analysed using Differential Scanning Calorimetry (DSC) (DSC Diamond from Perkin Elmer) and the degradation temperature was determined by Thermogravimetric Analysis (TGA) (TGA Q5000 IR from TA Instruments). The DSC experiments were carried out in nitrogen. Samples were first heated from $20^{\circ} \mathrm{C}$ to $200^{\circ} \mathrm{C}$ at a heating rate of $20^{\circ} \mathrm{C} / \mathrm{min}$. Then, a step of cooling between $200^{\circ} \mathrm{C}$ and $20^{\circ} \mathrm{C}$ at a cooling rate of $20^{\circ} \mathrm{C} / \mathrm{min}$ was carried out. Finally, a second heating took place between $20^{\circ} \mathrm{C}$ and $200^{\circ} \mathrm{C}$, again at $20^{\circ} \mathrm{C} / \mathrm{min}$. TGA experiments were conducted in air. Samples were heated from $50^{\circ} \mathrm{C}$ to $800^{\circ} \mathrm{C}$ at a heating rate of $20^{\circ} \mathrm{C} / \mathrm{min}$.

\subsubsection{Polymer extraction}

After lyophilization, the dry biomass was homogenized in a mortar. A mass of cells $(5 \mathrm{~g})$ was resuspended in $50 \mathrm{~mL}$ of chloroform in $100 \mathrm{~mL}$ capped glass flasks and magnetically stirred at $4^{\circ} \mathrm{C}$ for $36 \mathrm{~h}$. The content of the flasks was filtered under vacuum, through cellulose filters (Rotilabo-round filters type 114A, 3-5 $\mu \mathrm{m}$ pore, $90 \mathrm{~mm}$ in diameter from Carl Roth $\mathrm{GmbH}$ ) to separate the cellular debris. The chloroform containing the solubilized PHA was slowly poured into a $1 \mathrm{~L}$ Erlenmeyer containing $400 \mathrm{~mL}$ of previously cooled $\left(4^{\circ} \mathrm{C}\right)$ ethanol under very gentle agitation. The precipitate was allowed to settle for 1-2 h. Final recovery was attained under vacuum filtration using the same type of filters. 
The recovered precipitate was poured into glass Petri dishes for solvent evaporation during 24 hours at room temperature.

\section{Results and discussion}

\subsection{Shake flask assays}

\subsubsection{Precursor selection}

Gamma-butyrolactone (GBL) and 1,4-butanediol were tested as precursors for the production of the $4 \mathrm{HB}$ monomer by $B$. sacchari. Table 1 shows the results of the polymer production and composition in one-step cultivations carried out in shake-flasks with glucose $(20 \mathrm{~g} / \mathrm{L})$ and the precursor $(5 \mathrm{~g} / \mathrm{L})$ being added before the on-set of polymer accumulation. When 1, 4-butanediol was used, the copolymer content after $27 \mathrm{~h}$ was $54 \%(w / w)$, but no $4 \mathrm{HB}$ units were detected by GC analysis. With GBL, slightly higher biomass and PHA concentrations were obtained resulting in a similar polymer content of $55 \%$, however the GC analysis of the polymer revealed the presence of a peak with the same retention time as the standard (methyl-4-hydroxybutyrate). As the acidic methanolysis of GBL originates methyl-4-hydroxybutyrate, the quantification of the $4 \mathrm{HB}$ molar $\%$ in the polymer was carried out with the purified polymer instead of using the cell pellet as it may still contain GBL residues. Analysis by GC of the $4 \mathrm{HB}$ incorporation in the polymer revealed ca 1 molar $\%$ of $4 \mathrm{HB}$. GBL was thus chosen as precursor for the production of $\mathrm{P}(3 \mathrm{HB}-\mathrm{co}-4 \mathrm{HB})$.

\subsubsection{Evidence of $4 \mathrm{HB}$ incorporation in the polymer by ${ }^{1} \mathrm{H}$ NMR}


Selected samples of PHAs produced by B.sacchari using GBL as precursor for the $4 \mathrm{HB}$ monomer synthesis along with glucose or WSH as main C-source, were purified and analyzed by ${ }^{1} \mathrm{H}$ NMR to confirm the presence of the $4 \mathrm{HB}$ monomer and quantify its incorporation in the polymer. The ${ }^{1} \mathrm{H}$ NMR spectra showed that the polymers are composed of two monomer units, $3 \mathrm{HB}$ and $4 \mathrm{HB}$, and the spectrum signals (Fig. 1) appear identical to those obtained for $\mathrm{P}(3 \mathrm{HB}$ co-4HB) by other authors $[19,25]$. The fraction of each monomer was calculated from the areas of the $4.11 \mathrm{ppm}$ signal from $4 \mathrm{HB}$ and the $5.26 \mathrm{ppm}$ signal from 3HB ( $\mathrm{C}$ and $\mathrm{B}$ in Fig.1), bearing in mind that the $4 \mathrm{HB}$ and the $3 \mathrm{HB}$ signals correspond, respectively to two and one hydrogen atoms.

\subsubsection{Effect of GBL concentration on cell growth}

To determine maximum allowed GBL concentrations in the cultivation medium, the effect of GBL concentration on the maximum specific growth rate $\left(\mu_{\max }\right)$ of B. sacchari was assessed. GBL concentrations up to $5 \mathrm{~g} / \mathrm{L}$ do not affect $\mu_{\max }$ (Fig.2). Above this concentration, a continued decrease of $\mu_{\max }$ from 0.32 to $0.19 \mathrm{~h}^{-1}$ is observed as GBL concentrations increase from 5 to $40 \mathrm{~g} / \mathrm{L}$ suggesting that $B$. sacchari cells are inhibited by GBL. The feeding strategy of GBL for the production of $\mathrm{P}(3 \mathrm{HB}-\mathrm{co}-4 \mathrm{HB})$ should thus be controlled so that high polymer productivities in long term fed-batch cultivations are attained.

\subsubsection{Effect of the glucose and GBL concentrations on the copolymer production and composition}

Shake flask cultures were carried out to investigate the effects of the carbon source and precursor (GBL) concentration on the cell growth and $\mathrm{P}(3 \mathrm{HB}-\mathrm{co}-$ 
4HB) production by $B$. sacchari. Table 2 shows the CDW, total polymer production (PHA) and polymer composition after $52 \mathrm{~h}$ of cultivation at different concentrations of glucose (0- $20 \mathrm{~g} / \mathrm{L})$ and GBL (0-15 g/L). Under these conditions it is observed that the homopolymer $\mathrm{P}(3 \mathrm{HB})$ was produced when glucose was used as the sole carbon source. The PHA cell content decreased as the ratio $\mathrm{GBL} /$ glucose increased. A decrease of CDW and PHA concentration is also observed at increasing GBL/glucose ratios except for a GBL concentration of $5 \mathrm{~g} / \mathrm{L}$, where a slight increase for the CDW and PHA concentration is noticed. This is probably due not only to the GBL toxicity above $5 \mathrm{~g} / \mathrm{L}$, but also to the decreasing glucose concentrations in the medium. The molar fractions of the $4 \mathrm{HB}$ unit in the copolymer increased from 0 to $1.8 \mathrm{~mol} \%$ with increasing gamma-butyrolactone concentration. These results are lower than the incorporations achieved under identical conditions by Mendonça et al, 2013 ( 9.1 molar \%) using 4- hydroxybutyric acid as precursor [22]. An assay was also carried out where GBL (10 g/L) was the sole carbon-source. In this case a higher 4HB incorporation of 4.6 molar \% was observed, however, as expected, very low polymer cell contents are attained $(7.1 \%)$. Moreover, this assay reveals that the monomer $3 \mathrm{HB}$ is also synthesized from GBL since 95.4 molar $\%$ of the total polymer produced in these conditions is $3 \mathrm{HB}$.

A possible biosynthesis pathway for the production of $\mathrm{P}(3 \mathrm{HB}-\mathrm{co}-4 \mathrm{HB})$ from sugars and gamma butyrolactone (precursor) by Burkholderia sacchari involves the conversion of GBL to either acetyl-CoA or 4-hydroxybutyryl-CoA and the metabolism of sugars to acetyl-CoA by the Entner Doudoroff pathway (hexoses) or through the pentose phosphate pathway (pentoses), both known to be 
present in Burkholderia spp. [26] [27]. Gamma-butyrolactone (GBL) is known as a suitable precursor for the biosynthesis of $4 \mathrm{HB}$ in Cupriavidus necator (former Ralstonia eutropha and Alcaligenes eutrophus) [12] and Hydrogenophaga pseudoflava [18]. During metabolism of GBL, the lactone ring is opened to yield 4-hydroxybutyric acid. Choi et al (1999) working with Hydrogenophaga pseudoflava [18] and Kunioka et al (1989) working with Cupriavidus necator [28] suggest that ring opening probably occurs within the cell. A pathway for $\mathrm{P}(3 \mathrm{HB}-$ co-4HB) synthesis proposed by Valentin et al, (1995), in Cupriavidus necator [29] possibly also valid for species like Burkholderia sacchari that produce copolymers with $4 \mathrm{HB}$ molar fractions less than $50 \% .(\mathrm{mol} / \mathrm{mol})$ involves only partial conversion of 4-hydroxybutyric acid to 4-hydroxybutyryl-CoA. The main fraction of 4-hydroxybutyric acid is catabolized further to succinic acid semialdehyde and succinic acid and converted to acetyl-CoA from which 3hydroxybutyryl-CoA is synthesized. As a last step, 3-hydroxybutyryl-CoA and 4hydroxybutyryl-CoA are polymerized to form the copolymer $\mathrm{P}(3 \mathrm{HB}-\mathrm{co}-4 \mathrm{HB})$ through the action of a PHA synthase.

\subsection{Fed-batch cultures}

\subsubsection{Fed -batch cultivations for the production of $\mathrm{P}(3 \mathrm{HB}-\mathrm{co}-4 \mathrm{HB})$ using glucose as C-source (control)}

To be able to reach high-cell density cultures and improve copolymer productivity on wheat straw hydrolysates, fed-batch cultures have been carried out. The fed-batch strategy adopted in this study for the C-source addition was similar to the one implemented in a previous study aiming at the production of the homopolymer $\mathrm{P}(3 \mathrm{HB})$ based on wheat straw hydrolysates [21]. An 
automated carbon-source addition was triggered by a decrease of the stirring speed which happens due to the increase of the dissolved oxygen concentration when the C-source in the cultivation broth is exhausted (DO-stat). When using wheat straw hydrolysates, glucose was consumed preferentially followed by xylose and arabinose (carbon catabolite repression). The metabolism of glucose demanded a high rate of oxygen consumption which is translated in a high stirring speed value (1200 rpm is the maximum allowed by the equipment). Upon glucose exhaustion, the stirring speed value dropped automatically as xylose and arabinose consumption proceeded at a lower rate (the stirring speed goes to a lower plateau indicating a lower metabolic activity thus less oxygen is needed). To allow for pentose consumption, a stirring speed value triggering automatic feeding was selected at $900 \mathrm{rpm}$. This value enabled for complete consumption of the glucose in the medium and for partial consumption of xylose and arabinose before another pulse of fresh feed was added. The developed strategy fully succeeded in avoiding the accumulation of xylose and arabinose in the cultivation medium to inhibitory levels.

Glucose was first used as model C-source for copolymer P(3HB-co-4HB) production with the purpose of obtaining reference data for the subsequent cultivations on wheat straw hydrolysates (WSH). The best timing for GBL addition, the magnitude of the pulse and the GBL addition rate were addressed beforehand to assess the effect of these conditions on copolymer volumetric productivity and composition (unpublished results, paper in preparation). A feeding strategy featuring manual addition of a pulse of GBL (8 $\mathrm{g} / \mathrm{L})$ followed by a $2.3 \mathrm{~g} / \mathrm{h}$ GBL continuous supply and an automatic feeding of the carbon source using the DO-stat method (900 rpm) was chosen, as it allowed for high 
copolymer productivities and compositions. GBL addition took place during the polymer accumulation phase when the CDW attained ca. $75-80 \mathrm{~g} / \mathrm{L}$ and the polymer cell content was 50-55 \% (w/w). The results obtained are shown in Fig. 3 and summarized on Table 3 . After 52 hours cultivation under these conditions the cell concentration (CDW), copolymer concentration (PHA) and PHA content were $78 \mathrm{~g} / \mathrm{L}, 37 \mathrm{~g} / \mathrm{L}$ and $45 \%$, respectively. The maximum attained $4 \mathrm{HB}$ incorporation in the polymer was 4.7 molar \%. The CDW and the PHA concentration only slightly changed after GBL addition probably because the GBL concentration remained constant above the inhibitory level ( $5 \mathrm{~g} / \mathrm{L})$, at approximately $10 \mathrm{~g} / \mathrm{L}$. In this respect the cultivation behaved differently as compared to its counterpart (on glucose and in the absence of GBL) for the production of the homopolymer $\mathrm{P}(3 \mathrm{HB})$. In the later, the CDW and $\mathrm{PHA}$ concentration increased during the whole process to reach 138 and $101 \mathrm{~g} / \mathrm{L}$, respectively after $42 \mathrm{~h}$ cultivation (Table 3 ). These results confirm a certain degree of toxicity to $B$. sacchari by $\mathrm{GBL}$ at $10 \mathrm{~g} / \mathrm{L}$.

The addition of a small quantity (2 $\mathrm{g} / \mathrm{L})$ of propionate $[12,30]$ or acetate [12] is reported in literature to stimulate the incorporation of $4 \mathrm{HB}$ monomers in the copolymer synthesized by C. necator. Lee et al. (2000) have shown that a supplemental addition of propionate induced significantly the PHA synthase activity as well as the acetyl-CoA concentration. The increased overflow of acetyl-CoA probably from the ketolysis of propionate, inhibits the ketolysis of 4hydroxybutyryl-CoA to acetyl-CoA, maintaining a high concentration of that intermediate in the cells for the synthesis of the $\mathrm{P}(3 \mathrm{HB}-\mathrm{co}-4 \mathrm{HB})$ copolymer. Moreover, the increased concentration of the intermediates 3HB from GBL and 
propionate and $4 \mathrm{HB}$ from GBL, also seem to induce the activity of PHA synthase by substrate induction [30].

In this work two fed-batch cultivations were carried out using propionic acid and acetic acid as stimulators. The stimulator was added simultaneously with the first pulse of GBL to attain a concentration of $2 \mathrm{~g} / \mathrm{L}$ in the cultivation medium. The GBL addition rate was $2.3 \mathrm{~g} / \mathrm{h}$ and glucose was added through the DO-stat method. The time course of the cultivations is shown in Fig. 4 and the summary of the results on Table 3. The cultivation with propionic acid (Fig 4A), reached a CDW, PHA concentration and PHA content of $82 \mathrm{~g} / \mathrm{L}, 32 \mathrm{~g} / \mathrm{L}$ and $39 \%$, respectively after $50 \mathrm{~h}$ and the $4 \mathrm{HB}$ reached a value of ca. 6.3 molar \%. GBL concentrations attained inhibitory concentrations of $15 \mathrm{~g} / \mathrm{L}$. When acetic acid was used as a stimulator (Fig. 4B), after addition of a $2 \mathrm{~g} / \mathrm{L}$ pulse, a sharp decrease of the CDW and PHA content was observed to values of $60 \mathrm{~g} / \mathrm{L}$ and $19 \%$, respectively, after $50 \mathrm{~h}$ cultivation, while the $4 \mathrm{HB}$ reached values of circa 12 molar \%. GBL concentrations remained in the range $12-15 \mathrm{~g} / \mathrm{L}$ reaching thus inhibitory levels. This study indicates that similarly to what was observed by other authors with $C$. necator, the addition of a small amount of acetic or propionic acids enhances the $4 \mathrm{HB}$ incorporation and directs the metabolism of GBL towards the production of $4 \mathrm{HB}$ units. The highest $4 \mathrm{HB}$ incorporations were achieved with acetic acid, but the later seems to be more toxic to the cells than propionic acid since the final values of CDW and PHA content are significantly lower, leading to much lower productivities.

Towards the end of cultivations and especially when the concentration of GBL attained values above $12-15 \mathrm{~g} / \mathrm{L}$, the cell metabolism slowed down. From that 
stage ( $\mathrm{t} \approx 45 \mathrm{~h}$ cultivation) onwards glucose was being oversupplied, i.e. the DOstat mode became inadequate for feeding control. To further improve both GBL and glucose addition rates, a fed-batch cultivation strategy was designed using as feed a $500 \mathrm{~mL}$ solution consisting of a mixture of GBL and glucose. The applied GBL/glucose ratio and feed rate of $0.2(\mathrm{w} / \mathrm{w})$ and $20 \mathrm{~mL} / \mathrm{h}$, respectively, were calculated based on the average GBL and glucose specific consumption rates. Similarly to the strategy described above, a first pulse of GBL (ca $8 \mathrm{~g} / \mathrm{L}$ ) was added manually at a CDW of $75-80 \mathrm{~g} / \mathrm{L}$ during the accumulation phase. At that moment, the glucose feed $(600 \mathrm{~g} / \mathrm{L})$ was replaced with the mixture of GBL and glucose. The results are shown in Fig 5. Indeed the same 4HB molar composition of ca $5 \%(\mathrm{~mol} / \mathrm{mol})$ was attained as in the case of the addition of glucose via DO-stat combined with a continuous flow of GBL of $2.3 \mathrm{~g} / \mathrm{h}$ (Fig. 3), however a more stable glucose concentration could be maintained throughout the cultivation.

\subsubsection{Fed-batch cultivation for the production of $\mathrm{P}(3 \mathrm{HB}-\mathrm{co}-4 \mathrm{HB})$ with wheat straw hydrolysates as $\mathrm{C}$-source}

Fed-batch cultivations aiming at $\mathrm{P}(3 \mathrm{HB}-\mathrm{co}-4 \mathrm{HB})$ production were carried out using wheat straw hydrolysates (WSH). An inhibitors-free hydrolysate containing $465.3 \mathrm{~g} / \mathrm{L}$ glucose, $146.3 \mathrm{~g} / \mathrm{L}$ xylose and $41.5 \mathrm{~g} / \mathrm{L}$ arabinose was tested as C-source. This hydrolysate had been previously used as C-source for $\mathrm{P}(3 \mathrm{HB})$ production [21] (Table 4). The feeding period was carried out with a first pulse of $8 \mathrm{~g} / \mathrm{L}$ followed by a continuous GBL flow rate of $2.3 \mathrm{~g} / \mathrm{h}$ and DO-stat addition of the C-source. The time course of the cultivation is shown in Fig. 6A and the summary of the results on Table 3. Fig.6B shows the cultivation where 
$3 \mathrm{~mL}$ of propionic acid was added simultaneously with the first pulse of GBL to attain a concentration of $2 \mathrm{~g} / \mathrm{L}$ stimulator in the cultivation medium.

At the moment of GBL addition, the CDW, PHA concentration and PHA content were $82 \mathrm{~g} / \mathrm{L}, 27.4 \mathrm{~g} / \mathrm{L}$ and $33.6 \%$, respectively and remained approximately constant throughout the cultivation. The GBL concentrations attained values around $10-15 \mathrm{~g} / \mathrm{L}$, i.e. above $5 \mathrm{~g} / \mathrm{L}$, thus reaching inhibitory levels. The $4 \mathrm{HB}$ attained a value of ca. 5 and $5.5 \%$ molar $\%$ after $49 \mathrm{~h}$ cultivation with and without stimulator, respectively. Similarly to the cultivations on glucose, addition of propionic acid enhanced the $4 \mathrm{HB} \%$ in the polymer, though to a lesser extent. Although a similar copolymer composition was achieved compared to the cultivations on glucose (Table 3), lower productivities were obtained when using the hydrolysate as C-source. This is due to the presence of pentoses, namely xylose and arabinose in the hydrolysate (29\% of the total sugars) which are consumed at a lower rate compared to glucose, as reported earlier [21].

Table 4 summarizes the results of a previous cultivation for the production of $\mathrm{P}(3 \mathrm{HB})[21]$ and the results for $\mathrm{P}(3 \mathrm{HB}-\mathrm{co}-4 \mathrm{HB})$ production (this work), using the same wheat straw hydrolysate. In the case of the copolymer, the volumetric productivity was three-fold lower due to the toxic effect of gamma-butyrolactone since its concentration remained constant at approximately $10 \mathrm{~g} / \mathrm{L}$. Indeed, as shown above, increasing concentrations of GBL lead to decreasing growth rates, which will result in lower productivities in prolonged fed-batch cultivations. 


\subsection{Molecular weights and thermal properties of $P(3 H B-c 0-4 H B)$}

Copolymers $\mathrm{P}(3 \mathrm{HB}-\mathrm{co}-4 \mathrm{HB})$ produced by $B$. sacchari containing different $4 \mathrm{HB}$ molar fractions were characterized and the properties listed on Table 5. A decrease of the molecular weight from $7.9 \times 10^{5}$ to $4.5 \times 10^{5}$ Da was observed as the $4 \mathrm{HB}$ increased from 0 to 7.8 molar \% while the polydispersity $(\mathrm{Mw} / \mathrm{Mn})$ increased from 1.4 to 1.7 . The decrease of the average polymer chain length at increasing $4 \mathrm{HB}$ molar fractions is similar to the findings of other authors using different strains [31-32].

Thermal characterization of the copolymers was carried out by Differencial Scanning Calorimetry (DSC) and Thermogravimetric Analysis (TGA). A decrease both of the melting temperature $(\mathrm{Tm})$ and the crystallization temperature $(T C)$ was observed with higher $4 \mathrm{HB}$ molar fractions. The same happened with the degradation temperature (Tdeg) of the polymers. Similar observations have been reported by other authors [14, 31].

\section{Conclusions}

Burkholderia sacchari is able to produce the $\mathrm{P}(3 \mathrm{HB}-\mathrm{co}-4 \mathrm{HB})$ copolymer upon addition of gamma-butyrolactone (GBL) to the medium. Cell growth inhibition is observed at GBL concentrations above $10 \mathrm{~g} / \mathrm{L}$ and thus the strategy for feeding the precursor requires strict control. Maximum $\mathrm{P}(3 \mathrm{HB}-\mathrm{co}-4 \mathrm{HB})$ concentrations of $37 \mathrm{~g} / \mathrm{L}$ containing ca. 5 molar $\%$ of $4 \mathrm{HB}$, corresponding to a volumetric productivity of $0.7 \mathrm{~g} / \mathrm{L} \mathrm{h}$, were achieved in fed-batch cultures on glucose when a first pulse of GBL (8 $\mathrm{g} / \mathrm{L})$ was added during the polymer accumulation phase followed by a continuous flow of GBL $(2.3 \mathrm{~g} / \mathrm{h})$. A pulse of propionic acid $(2 \mathrm{~g} / \mathrm{L})$ 
together with the initial pulse of GBL enhanced the $4 \mathrm{HB}$ incorporation to ca. 6.3 molar \% while attaining a volumetric productivity and polymer content of $0.6 \mathrm{~g} / \mathrm{L}$ h and $39 \%$, respectively.

The same feeding conditions on WSH as C-source revealed maximum polymer concentrations, volumetric productivities, polymer content and composition of $24 \mathrm{~g} / \mathrm{L}, 0.5 \mathrm{~g} / \mathrm{L} \mathrm{h}, 27 \%$ and 5 molar \% 4HB. On WSH, a similar copolymer composition was thus achieved compared to the glucose (control), however lower productivities were attained due to the lower polymer production rate on xylose and arabinose.

This is the first work reporting the ability of $B$. sacchari to synthesize the $4 \mathrm{HB}$ monomer from GBL to produce the $\mathrm{P}(3 \mathrm{HB}-\mathrm{co}-4 \mathrm{HB})$ copolymer. Moreover, the feasibility of using fed-batch cultivation for the production of the copolymer $\mathrm{P}(3 \mathrm{HB}-\mathrm{co}-4 \mathrm{HB})$ based on a lignocellulosic agricultural residue was demonstrated.

\section{Acknowledgements}

This work has received funding from the European Union $7^{\text {th }}$ Framework Programme (FP7/2007-2013) under Grant Agreement number 246449 'BUGWORKERS'. The authors would like to acknowledge biorefinery.de $\mathrm{GmbH}$ (Germany) for providing the hydrolysates, TECNALIA (Miñano -Spain) for the molecular weight determination, AIMPLAS (Valencia- Spain) for the DSC and TGA determinations and Fundação para a Ciência e Tecnologia, Portugal for financial support (fellowships SFRH/BPD/68587/2010 and SFRH/BPD/26678/2006). 


\section{References}

[1] A. Steinbüchel, B. Füchtenbusch, Trends in Biotechnology, 16 (1998) 419-427.

[2] K. Sudesh, H. Abe, Y. Doi, Progress in Polymer Science, 25 (2000) 1503-1555.

[3] X. Gao, J.-C. Chen, Q. Wu, G.-Q. Chen, Current Opinion in Biotechnology, 22 (2011) 768774.

[4] L.A. Madden, A.J. Anderson, J. Asrar, Macromolecules 31 (1998) 5660-5667.

[5] S.J. Park, W.S. Ahn, P.R. Green, S.Y. Lee, Biotechnol. Bioeng., 74 (2001) 81-86.

[6] A. Steinbüchel, PHB and other polyhydroxyalkanoic acids, in: R. Rehm HJ, M. Galbe (Eds.)

Biotechnology products of primary metabolism, Biotechnology VCH, Weinheim, 1996, pp. 404464.

[7] G.-Q. Chen, Plastics Completely Synthesized by Bacteria: Polyhydroxyalkanoates, in: G.-Q. Chen (Ed.) Plastics from Bacteria: natural Functions and Applications, Springer-Verlag Berlin Heidelberg, 2010, pp. 17-37.

[8] A. Steinbüchel, H.E. Valentin, FEMS Microbiology Letters, 128 (1995) 219-228.

[9] S. Chanprateep, K. Buasri, A. Muangwong, P. Utiswannakul, Polymer Degradation and Stability, 95 (2010) 2003-2012.

[10] D.P. Martin, S.F. Williams, Biochemical Engineering Journal, 16 (2003) 97-105.

[11] J.M.B.T. Cavalheiro, R.S. Raposo, M.C.M.D. de Almeida, M.T. Cesário, C. Sevrin, C. Grandfils, M.M.R. da Fonseca, Bioresource Technology, 111 (2012) 391-397.

[12] J.S. Kim, B.H. Lee, B.S. Kim, Biochemical Engineering Journal, 23 (2005) 169-174.

[13] Hiramitsu M, Koyama N, Y. Doi, Biotechnol. Letters, 15 (1993) 461-464.

[14] Y. Saito, S. Nakamura, M. Hiramitsu, Y. Doi, Polym. Int., 39 (1996) 169-174.

[15] W.-H. Lee, M.N.M. Azizan, K. Sudesh, Polymer Degradation and Stability, 84 (2004) 129134.

[16] C.-Y. Loo, K. Sudesh, International Journal of Biological Macromolecules, 40 (2007) 466471.

[17] G. Renner, K. Pongratz, G. Braunegg, Food Technol. Biotechnol. , 34 (1996) 91-95.

[18] M.H. Choi, S.C. Yoon, R.W. Lenz, Applied and Environmental Microbiology, 65 (1999) 15701577.

[19] H. Valentin, D. Dennis, J. Biotechnol., 58 (1997) 33-38.

[20] L.F. Silva, M.K. Taciro, M.E. Michelin Ramos, J.M. Carter, J.G.C. Pradella, J.G.C. Gomez, Journal of Industrial Microbiology \& Biotechnology, 31 (2004) 245-254.

[21] M.T. Cesário, R.S. Raposo, M.C. Almeida, F. van Keulen, B.S. Ferreira, M.M.R. da Fonseca, New Biotechnology, 31 (2014) 104-113.

[22] T.T. Mendonça, J.G.C. Gomez, E. Buffoni, R.J. Sánchez Rodriguez, J. Schripsema, M.S.G. Lopes, L.F. Silva, Journal of Applied Microbiology, 116 (2014) 815-829.

[23] R.S. Rocha, L. Silva, M. Taciro, J.C. Pradella, World Journal of Microbiology and Biotechnology, 24 (2008) 427-431.

[24] B.S. Kim, S.C. Lee, S.Y. Lee, H.N. Chang, Y.K. Chang, S.I. Woo, Biotechnology and Bioengineering, 43 (1994) 892-898.

[25] S. Chanprateep, Y. Katakura, S. Visetkoop, H. Shimizu, S. Kulpreecha, S. Shioya, Journal of Industrial Microbiology \& Biotechnology, 35 (2008) 1205-1215.

[26] M.S.G. Lopes, R.K.B. Freire, K. Chouman, J.G.C. Gomez, L.F.d. Silva, in: International Symposium on Biopolymers, Stuttgart, 2010, pp. 72.

[27] M. Lopes, G. Gosset, R. Rocha, J. Gomez, L. Ferreira da Silva, Current Microbiology, 63

(2011).

[28] M. Kunioka, Y. Kawaguchi, Y. Doi, Appl Microbiol Biotechnol, 30 (1989) 569-573

[29] H.E. Valentin, G. Zwingmann, A. Schönebaum, A. Steinbüchel, European Journal of

Biochemistry, 227 (1995) 43-60.

[30] Y.-H. Lee, M.-S. Kang, Y.-M. Jung, Journal of Bioscience and Bioengineering, 89 (2000) 380383. 
[31] H.-L. Chai, R. Ahmad, A.R.M. Yahya, M.I.A. Majid, A.A. Amirul, African Journal of Biotechnology, 8 (2009) 4189-4196.

[32] S. Vigneswari, S. Vijaya, M. Majid, K. Sudesh, C. Sipaut, M. Azizan, A. Amirul, Journal of Industrial Microbiology and Biotechnology, 36 (2009) 547-556. 


\section{Captions to illustrations}

Table 1: Growth, production and $\mathrm{P}(3 \mathrm{HB}-\mathrm{co}-4 \mathrm{HB})$ composition results obtained with different $4 \mathrm{HB}$ precursors.

Table 2: Effect of GBL and glucose concentrations on the total biomass, accumulated polymer and copolymer composition (shake flask assays)

Table 3: Fed-batch cultivation results for the production of $\mathrm{P}(3 \mathrm{HB})$ and $\mathrm{P}(3 \mathrm{HB}-\mathrm{co}-4 \mathrm{HB})$

Table 4: Homo- and co-polymer production based on wheat straw hydrolysate

Table 5: Molecular weight and thermal properties of $\mathrm{P}(3 \mathrm{HB}-\mathrm{co}-4 \mathrm{HB})$ produced by B.sacchari.

Figure 1: ${ }^{1} \mathrm{H}$ NMR spectrum of $\mathrm{P}(3 \mathrm{HB}-\mathrm{co}-4 \mathrm{HB})$ produced by Burkholderia sacchari

Figure 2: Effect of GBL concentration on the Burkholderia sacchari maximum specific growth rate

Figure 3: Cell growth, PHA production and composition and glucose and GBL consumption in a 2L fed-batch cultivation using DO-stat addition of glucose. A) no GBL addition; B) with GBL addition during the accumulation phase: a pulse of $\mathrm{GBL}$ (8 $\mathrm{g} / \mathrm{L}$ ) followed by a continuous GBL addition $(2.3 \mathrm{~g} / \mathrm{h})$. CDW $(\mathrm{g} / \mathrm{L})\left({ }^{-}\right)$, 3HB $(\mathrm{g} / \mathrm{L})\left({ }^{-}\right)$,

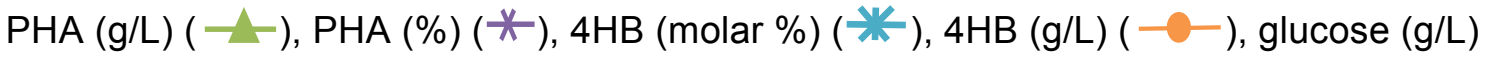
$(-), \mathrm{GBL}(\mathrm{g} / \mathrm{L})(--), \% \mathrm{DO}(-)$, stirring speed, rpm ( -$)$ and volume feed ( ) the dashed vertical line indicates the moment of GBL addition.

Figure 4: Cell growth, $\mathrm{P}(3 \mathrm{HB}-\mathrm{co}-4 \mathrm{HB})$ production and composition and glucose and GBL consumption in a $2 \mathrm{~L}$ fed-batch cultivation using DO-stat addition of glucose and a GBL pulse (8 $\mathrm{g} / \mathrm{L})$ and a continuous $\mathrm{GBL}$ addition $(2.3 \mathrm{~g} / \mathrm{h})$ during the accumulation 
phase. A) $2 \mathrm{~g} / \mathrm{L}$ propionic acid, B) $2 \mathrm{~g} / \mathrm{L}$ acetic acid. CDW (g/L) $(-), 3 \mathrm{HB}(\mathrm{g} / \mathrm{L})($ ), PHA (g/L) (- - ), PHA (\%) (*), 4HB (molar \%) (*) $\left(^{*}\right.$, 4HB (g/L) (-- $)$, glucose $(g / L)(--), G B L(g / L)(--)$; the dashed vertical line indicates the moment of GBL addition.

Figure 5: Cell growth, $\mathrm{P}(3 \mathrm{HB}-\mathrm{co}-4 \mathrm{HB})$ production and composition and glucose and GBL consumption by $B$. sacchari in a $2 \mathrm{~L}$ fed-batch cultivation using as feed a blend of GBL and glucose (50/250; $\mathrm{g} / \mathrm{g})$ and a constant feed addition rate $(20 \mathrm{~mL} / \mathrm{h})$. CDW $(\mathrm{g} / \mathrm{L})\left(\smile^{-}\right)$, 3HB $(\mathrm{g} / \mathrm{L})\left({ }^{-}\right)$, PHA $(\mathrm{g} / \mathrm{L})\left({ }^{-}\right)$, PHA $(\%)(*), 4 \mathrm{HB}(\operatorname{molar} \%)\left(*^{*}\right)$, 4HB $(g / L)(--)$, glucose $(g / L)(-)$, GBL $(g / L)(--)$; the dashed vertical line indicates the moment of GBL addition.

Figure 6:Cell growth , $\mathrm{P}(3 \mathrm{HB}-\mathrm{co}-4 \mathrm{HB})$ production and composition using a GBL pulse $(8 \mathrm{~g} / \mathrm{L})$ and a continuous GBL addition $(2.3 \mathrm{~g} / \mathrm{h})$ and DO-stat addition of wheat straw hydrolysate. A: no stimulator addition, B: with $2 \mathrm{~g} / \mathrm{L}$ propionic acid addition. CDW (g/L) $\left(\sim^{-}\right), 3 \mathrm{HB}(\mathrm{g} / \mathrm{L})(--), \operatorname{PHA}(\mathrm{g} / \mathrm{L})(--), \operatorname{PHA}(\%)(*), 4 \mathrm{HB}(\operatorname{molar} \%)\left(*^{*}\right), 4 \mathrm{HB}$ $(g / L)(--)$, glucose $(g / L)(-)$, xylose $(g / L)(-\rightarrow)$, arabinose $(g / L)(-)$, $\operatorname{GBL}(\mathrm{g} / \mathrm{L})(--)$; the dashed vertical line indicates the moment of $\mathrm{GBL}$ addition. 


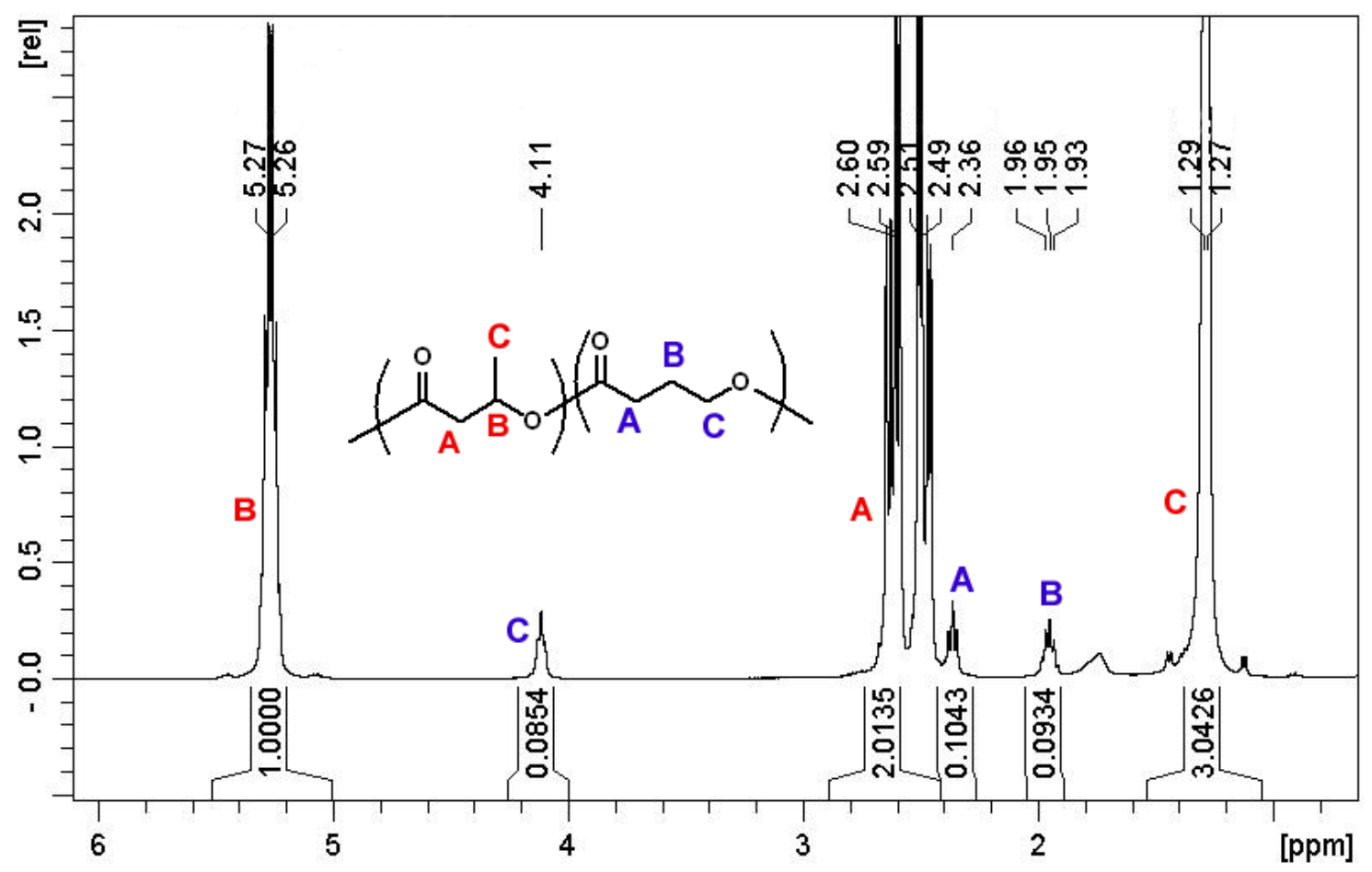

Figure 1

Production of poly (3-hydroxybutyrate-co-4-hydroxybutyrate) by Burkholderia sacchari using wheat straw hydrolysates and gamma-butyrolactone.

M. Teresa Cesário, Rodrigo S. Raposo, M. Catarina M.D. de Almeida, Frederik van Keulen, Bruno S. Ferreira, João P. Telo, M. Manuela R. da Fonseca 


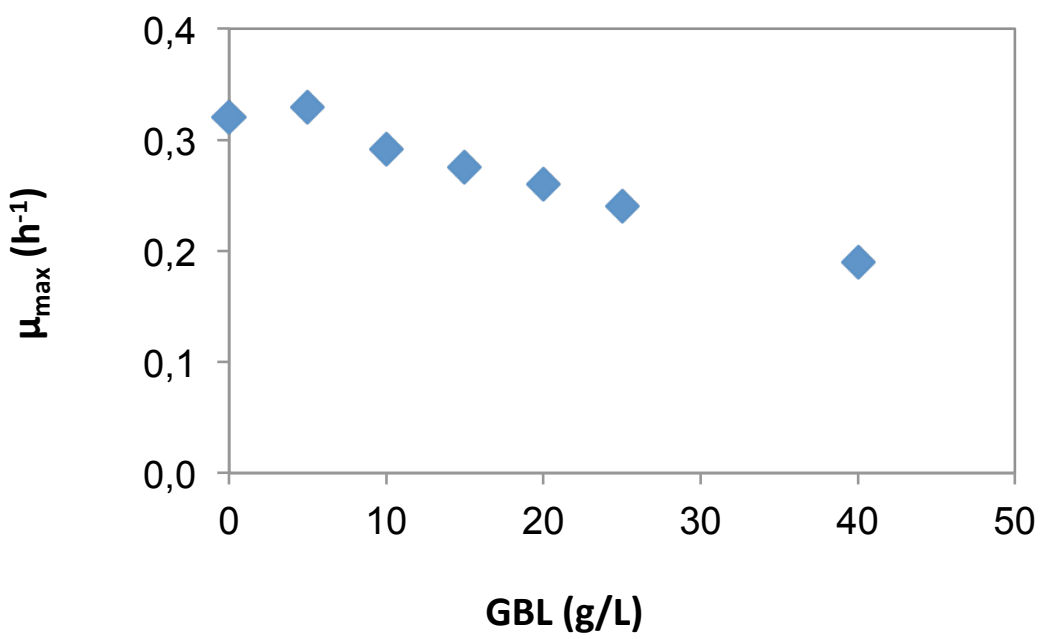

Figure 2

Production of poly (3-hydroxybutyrate-co-4-hydroxybutyrate) by Burkholderia sacchari using wheat straw hydrolysates and gamma-butyrolactone.

M. Teresa Cesário, Rodrigo S. Raposo, M. Catarina M.D. de Almeida, Frederik van Keulen, Bruno S. Ferreira, João P. Telo, M. Manuela R. da Fonseca 


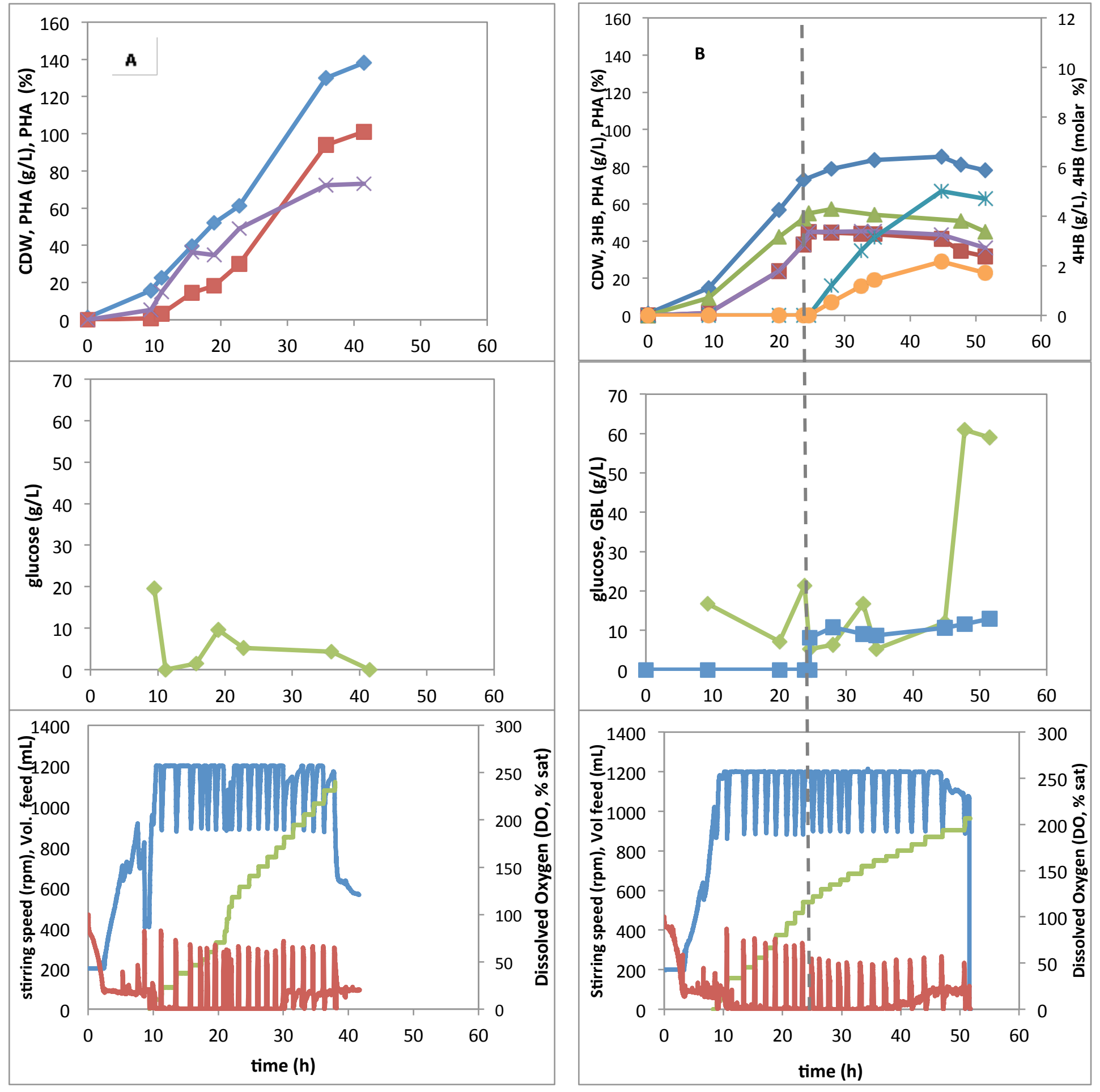

Figure 3:

Production of poly (3-hydroxybutyrate-co-4-hydroxybutyrate) by Burkholderia sacchari using wheat straw hydrolysates and gamma-butyrolactone.

M. Teresa Cesário, Rodrigo S. Raposo, M. Catarina M.D. de Almeida, Frederik van Keulen, Bruno S. Ferreira, João P. Telo, M. Manuela R. da Fonseca 

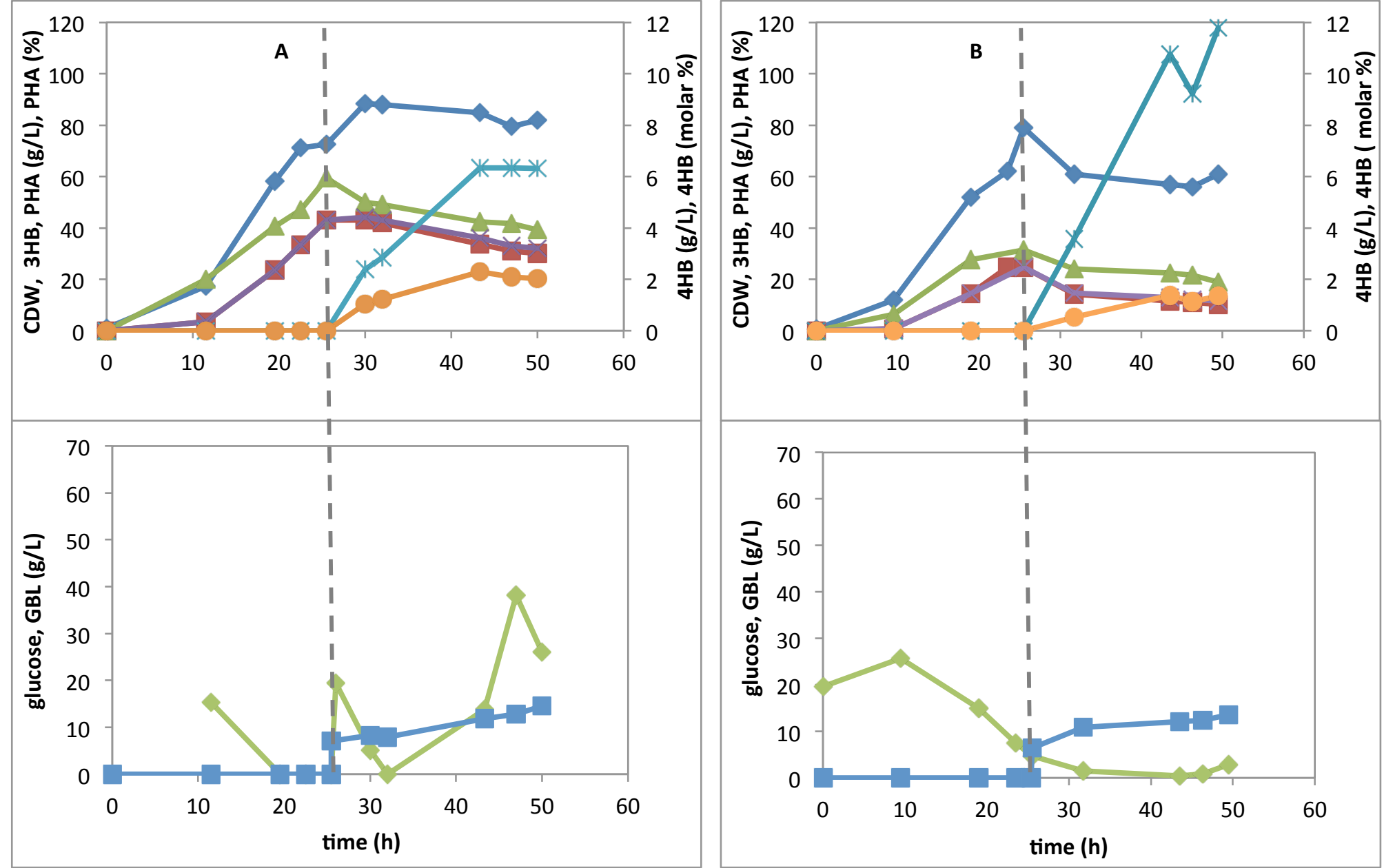

Figure 4:

Production of poly (3-hydroxybutyrate-co-4-hydroxybutyrate) by Burkholderia sacchari using wheat straw hydrolysates and gamma-butyrolactone.

M. Teresa Cesário, Rodrigo S. Raposo, M. Catarina M.D. de Almeida, Frederik van Keulen, Bruno S. Ferreira, João P. Telo, M. Manuela R. da Fonseca 


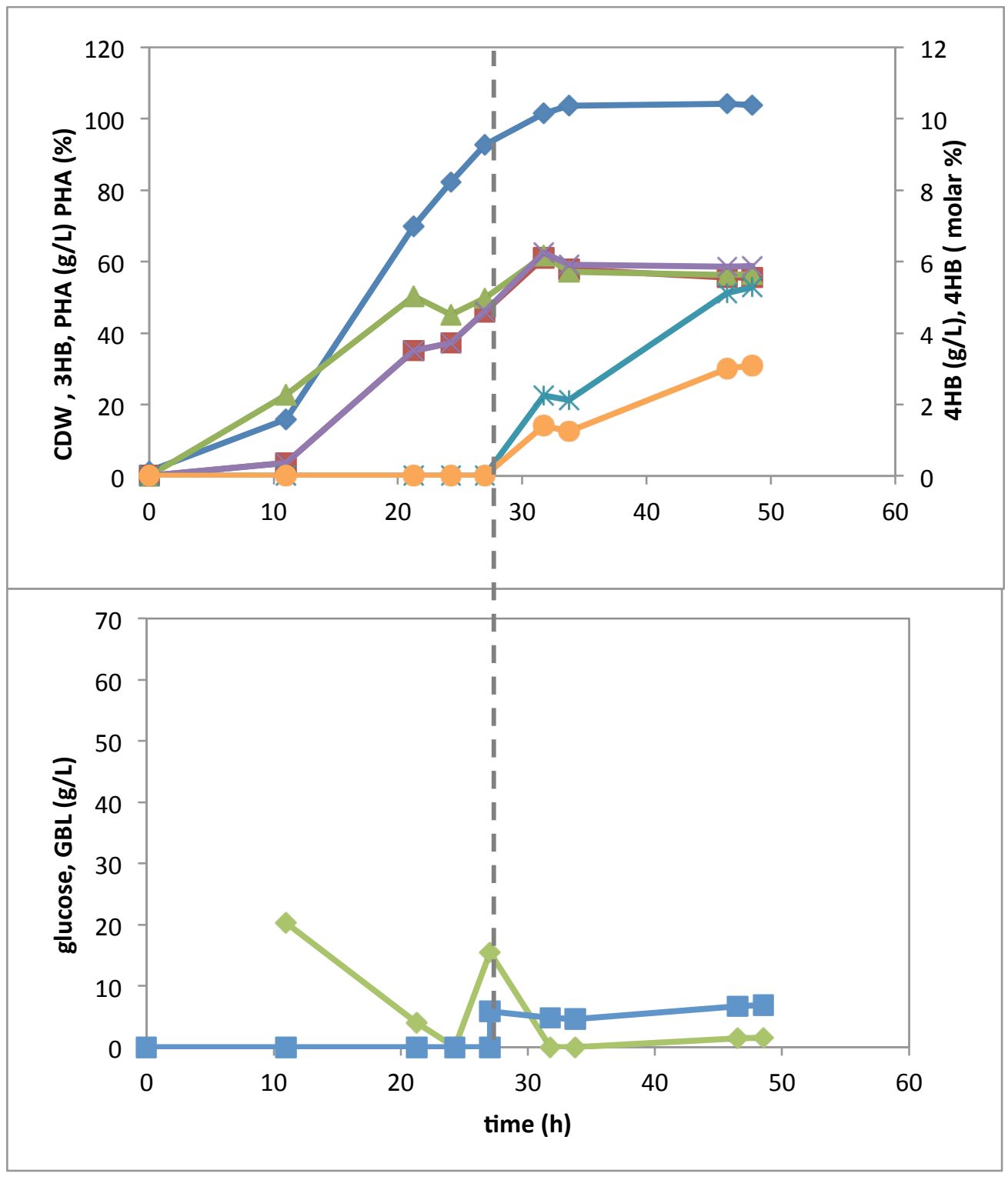

Figure 5:

Production of poly (3-hydroxybutyrate-co-4-hydroxybutyrate) by Burkholderia sacchari using wheat straw hydrolysates and gamma-butyrolactone.

M. Teresa Cesário, Rodrigo S. Raposo, M. Catarina M.D. de Almeida, Frederik van Keulen, Bruno S. Ferreira, João P. Telo, M. Manuela R. da Fonseca 

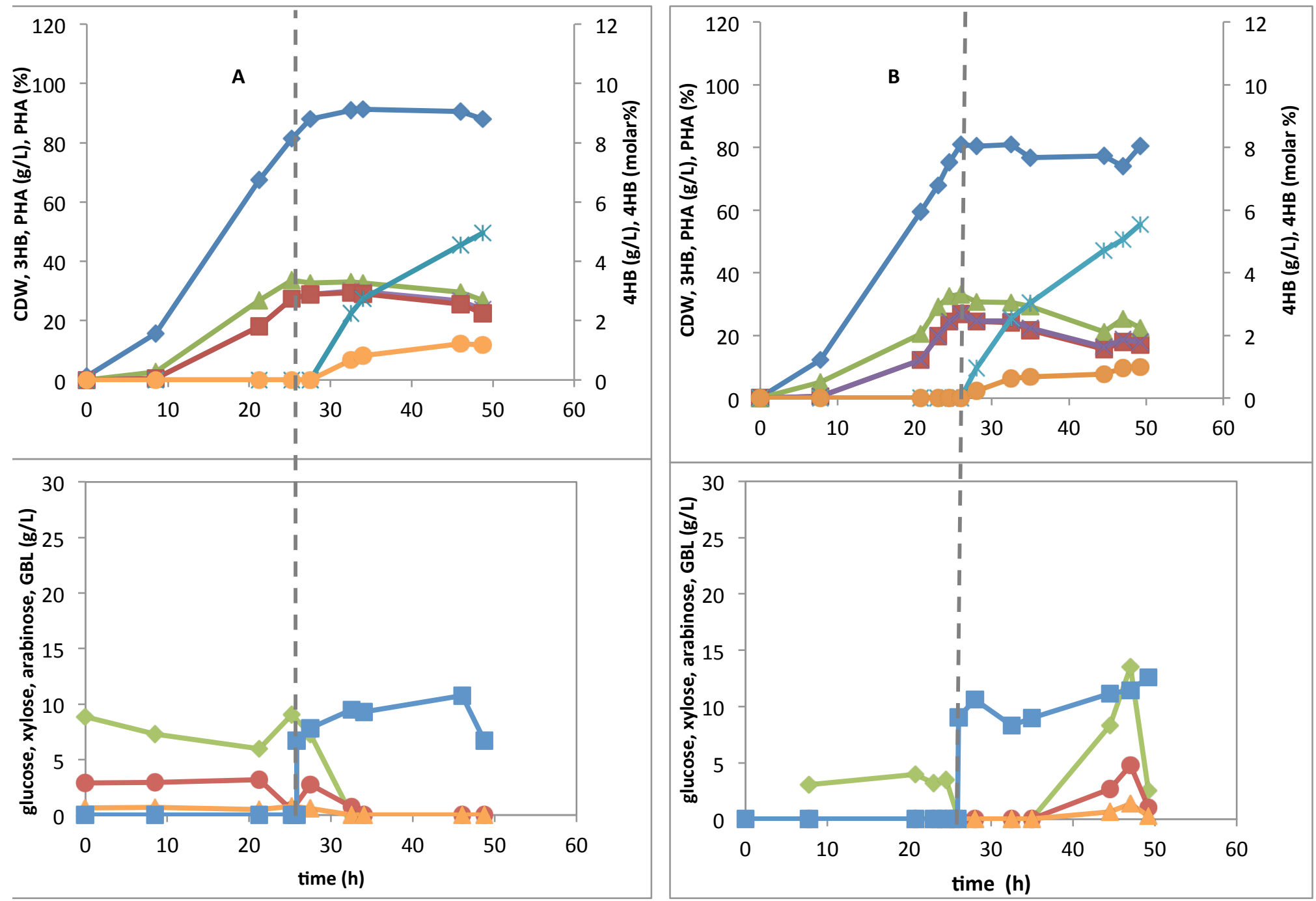

Figure 6:

Production of poly (3-hydroxybutyrate-co-4-hydroxybutyrate) by Burkholderia sacchari using wheat straw hydrolysates and gamma-butyrolactone.

M. Teresa Cesário, Rodrigo S. Raposo, M. Catarina M.D. de Almeida, Frederik van Keulen, Bruno S. Ferreira, João P. Telo, M. Manuela R. da Fonseca 
Table 1:

\begin{tabular}{|c|c|c|c|c|}
\hline Precursor & $\begin{array}{c}\text { CDW } \\
\text { (g/L) }\end{array}$ & $\begin{array}{c}\text { PHA } \\
\mathbf{( g / L )}\end{array}$ & $\begin{array}{c}\text { 3HB } \\
\text { (molar \%) }\end{array}$ & $\begin{array}{c}\text { 4HB } \\
\text { (molar \%) }\end{array}$ \\
\hline GBL & 8.0 & 4.3 & 99 & 1 \\
\hline 1,4-butanediol & 6.9 & 3.8 & 100 & 0 \\
\hline
\end{tabular}

Production of poly (3-hydroxybutyrate-co-4-hydroxybutyrate) by Burkholderia sacchari using wheat straw hydrolysates and gamma-butyrolactone.

M. Teresa Cesário, Rodrigo S. Raposo, M. Catarina M.D. de Almeida, Frederik van Keulen, Bruno S. Ferreira, João P. Telo, M. Manuela R. da Fonseca 
Table 2:

\begin{tabular}{|c|c|c|c|c|c|c|}
\hline $\begin{array}{c}\text { Glucose } \\
\mathbf{( g / L )}\end{array}$ & $\begin{array}{c}\text { GBL } \\
\mathbf{( g / L )}\end{array}$ & $\begin{array}{c}\text { CDW } \\
\mathbf{( g / L )}\end{array}$ & $\begin{array}{c}\text { PHA } \\
\mathbf{( g / L )}\end{array}$ & $\begin{array}{c}\text { \% PHA } \\
\mathbf{( w / w )}\end{array}$ & $\begin{array}{c}\text { 3HB } \\
\text { (molar \%) }\end{array}$ & $\begin{array}{c}\text { 4HB } \\
\text { (molar \%) }\end{array}$ \\
\hline 20 & 0 & 5.9 & 2.9 & 49.2 & 100.0 & 0.0 \\
\hline 15 & 5 & 6.6 & 3.1 & 47.0 & 99.0 & 1.0 \\
\hline 10 & 10 & 5.8 & 2.4 & 41.4 & 98.6 & 1.4 \\
\hline 5 & 15 & 2.7 & 0.9 & 33.3 & 98.2 & 1.8 \\
\hline 0 & 10 & 2.8 & 0.2 & 7.1 & 95.4 & 4.6 \\
\hline
\end{tabular}

Production of poly (3-hydroxybutyrate-co-4-hydroxybutyrate) by Burkholderia sacchari using wheat straw hydrolysates and gamma-butyrolactone.

M. Teresa Cesário, Rodrigo S. Raposo, M. Catarina M.D. de Almeida, Frederik van Keulen, Bruno S. Ferreira, João P. Telo, M. Manuela R. da Fonseca 
Table 3:

\begin{tabular}{|c|c|c|c|c|c|c|c|c|}
\hline C-source* $^{*}$ & Precursor** & Stimulator & $\begin{array}{c}\text { Culture } \\
\text { time }(\mathrm{h})\end{array}$ & $\begin{array}{c}\text { CDW } \\
(\mathrm{g} / \mathrm{L})\end{array}$ & $\begin{array}{c}\text { PHA } \\
(\mathrm{g} / \mathrm{L})\end{array}$ & $\begin{array}{c}\text { PHA content } \\
(\%)\end{array}$ & $\begin{array}{c}4 \mathrm{HB} \\
(\mathrm{molar} \%)\end{array}$ & $\begin{array}{c}\text { Prod.vol } \\
\mathrm{g} /(\mathrm{L} \cdot \mathrm{h})\end{array}$ \\
\hline glucose & - & - & 42 & 138 & 101 & 73 & 0.0 & 2.4 \\
\hline glucose & $\mathrm{GBL}$ & - & 52 & 78 & 37 & 45 & 4.7 & 0.7 \\
\hline glucose & GBL & $\begin{array}{c}2 \mathrm{~g} / \mathrm{L} \\
\text { propionic acid }\end{array}$ & 50 & 82 & 32 & 39 & 6.3 & 0.6 \\
\hline glucose & GBL & $\begin{array}{c}2 \mathrm{~g} / \mathrm{L} \\
\text { acetic acid }\end{array}$ & 50 & 61 & 12 & 19 & 11.8 & 0.2 \\
\hline WSH & GBL & - & 49 & 88 & 24 & 27 & 5.0 & 0.5 \\
\hline WSH & GBL & $\begin{array}{c}2 \text { g/L } \\
\text { propionic acid }\end{array}$ & 49 & 80 & 18 & 22 & 5.5 & 0.4 \\
\hline
\end{tabular}

* the carbon source (glucose or WSH) was added via DO-stat

** For co-polymer production, gamma-butyrolactone was added during the accumulation phase $(8 \mathrm{~g} / \mathrm{L}$ pulse followed by continuous addition at $2.3 \mathrm{~g} / \mathrm{h}$ )

Production of poly (3-hydroxybutyrate-co-4-hydroxybutyrate) by Burkholderia sacchari using wheat straw hydrolysates and gamma-butyrolactone.

M. Teresa Cesário, Rodrigo S. Raposo, M. Catarina M.D. de Almeida, Frederik van Keulen, Bruno S. Ferreira, João P. Telo, M. Manuela R. da Fonseca 
Table 4:

\begin{tabular}{|c|c|c|c|c|c|}
\hline Polymer & $\begin{array}{l}\text { Duration } \\
\text { of } \\
\text { cultivation } \\
\text { (h) }\end{array}$ & $\begin{array}{l}\text { CDW } \\
\text { (g/L) }\end{array}$ & $\begin{array}{l}\text { PHA } \\
(g / L)\end{array}$ & $\begin{array}{c}\text { PHA cell } \\
\text { content } \\
(\%)\end{array}$ & $\begin{array}{l}\text { Prod. vol. } \\
g /(L \cdot h)\end{array}$ \\
\hline $\mathrm{P}(3 \mathrm{HB})$ & 40 & 125 & 71 & 57 & 1.5 \\
\hline $\mathrm{P}(3 \mathrm{HB}-\mathrm{co}-6 \% 4 \mathrm{HB})$ & 49 & 88 & 24 & 27 & 0.5 \\
\hline
\end{tabular}

Production of poly (3-hydroxybutyrate-co-4-hydroxybutyrate) by Burkholderia sacchari using wheat straw hydrolysates and gamma-butyrolactone.

M. Teresa Cesário, Rodrigo S. Raposo, M. Catarina M.D. de Almeida, Frederik van Keulen, Bruno S. Ferreira, João P. Telo, M. Manuela R. da Fonseca 
Table 5

\begin{tabular}{|c|c|c|c|c|c|c|c|}
\hline Polymer & $\begin{array}{l}\mathrm{Mn} \\
(\mathrm{Da})\end{array}$ & $\begin{array}{l}\text { Mw } \\
\text { (Da) }\end{array}$ & PI & $\begin{array}{l}\mathrm{Tm} \\
\left({ }^{\circ} \mathrm{C}\right)\end{array}$ & $\begin{array}{l}\Delta \mathrm{Hm} \\
(\mathrm{J} / \mathrm{g})\end{array}$ & $\begin{array}{c}\text { Tc } \\
\left({ }^{\circ} \mathrm{C}\right)\end{array}$ & $\begin{array}{l}\text { Tdeg } \\
\left({ }^{\circ} \mathrm{C}\right)^{*}\end{array}$ \\
\hline$P(3 \mathrm{HB})$ & $5.8 \times 10^{5}$ & $7.9 \times 10^{5}$ & 1.4 & 171.7 & 94.6 & 68.8 & 278.92 \\
\hline $\mathrm{P}(3 \mathrm{HB}-\mathrm{co}-3.0 \%$ 4HB $)$ & $4.1 \times 10^{5}$ & $5.9 \times 10^{5}$ & 1.4 & - & - & - & - \\
\hline $\mathrm{P}(3 \mathrm{HB}-\mathrm{co}-4.6 \%$ 4HB) & $3.2 \times 10^{5}$ & $5.1 \times 10^{5}$ & 1.6 & 164.32 & 68.9 & 59.5 & 259.60 \\
\hline $\mathrm{P}(3 \mathrm{HB}-\mathrm{co-}-7.6 \%$ 4HB) & $2.7 \times 10^{5}$ & $4.5 \times 10^{5}$ & 1.7 & 158.8 & 76.6 & 56.7 & 256.27 \\
\hline
\end{tabular}

*Temperatures corresponding to the onset of weight loss (To).

Production of poly (3-hydroxybutyrate-co-4-hydroxybutyrate) by Burkholderia sacchari using wheat straw hydrolysates and gamma-butyrolactone.

M. Teresa Cesário, Rodrigo S. Raposo, M. Catarina M.D. de Almeida, Frederik van Keulen, Bruno S. Ferreira, João P. Telo, M. Manuela R. da Fonseca 